\title{
บUisuersily
}

\section{Novel combination of non-invasive morphological and solid-state characterisation of drug-loaded core-shell electrospun fibres}

Kazsoki, A., Farkas, A., Balogh-Weiser, D., Mancuso, E., Sharma, P., Lamprou, D., \& Zelkó, R. (2020). Novel combination of non-invasive morphological and solid-state characterisation of drug-loaded core-shell electrospun fibres. International Journal of Pharmaceutics, 587, [119706]. https://doi.org/10.1016/j.ijpharm.2020.119706

Link to publication record in Ulster University Research Portal

\section{Published in:}

International Journal of Pharmaceutics

Publication Status:

Published (in print/issue): 25/09/2020

DOI:

10.1016/j.ijpharm.2020.119706

\section{Document Version}

Author Accepted version

\section{General rights}

Copyright for the publications made accessible via Ulster University's Research Portal is retained by the author(s) and / or other copyright owners and it is a condition of accessing these publications that users recognise and abide by the legal requirements associated with these rights.

\section{Take down policy}

The Research Portal is Ulster University's institutional repository that provides access to Ulster's research outputs. Every effort has been made to ensure that content in the Research Portal does not infringe any person's rights, or applicable UK laws. If you discover content in the Research Portal that you believe breaches copyright or violates any law, please contact pure-support@ulster.ac.uk. 


\section{Journal Pre-proofs}

Novel combination of non-invasive morphological and solid-state characterisation of drug-loaded core-shell electrospun fibres

Adrienn Kazsoki, Attila Farkas, Diána Balogh-Weiser, Elena Mancuso,

Preetam K. Sharma, Dimitrios A. Lamprou, Romána Zelkó

PII:

S0378-5173(20)30690-6

DOI:

https://doi.org/10.1016/j.ijpharm.2020.119706

Reference:

IJP 119706

To appear in:

International Journal of Pharmaceutics

Received Date:

20 April 2020

Revised Date:

24 July 2020

Accepted Date:

25 July 2020

Please cite this article as: A. Kazsoki, A. Farkas, D. Balogh-Weiser, E. Mancuso, P.K. Sharma, D.A. Lamprou, R. Zelkó, Novel combination of non-invasive morphological and solid-state characterisation of drug-loaded coreshell electrospun fibres, International Journal of Pharmaceutics (2020), doi: https://doi.org/10.1016/j.ijpharm. 2020.119706

This is a PDF file of an article that has undergone enhancements after acceptance, such as the addition of a cover page and metadata, and formatting for readability, but it is not yet the definitive version of record. This version will undergo additional copyediting, typesetting and review before it is published in its final form, but we are providing this version to give early visibility of the article. Please note that, during the production process, errors may be discovered which could affect the content, and all legal disclaimers that apply to the journal pertain.

(C) 2020 Published by Elsevier B.V. 
3

4

Novel combination of non-invasive morphological and solid-state characterisation of drug-loaded core-shell electrospun fibres

Adrienn Kazsoki ${ }^{1}$, Attila Farkas ${ }^{2}$, Diána Balogh-Weiser ${ }^{2,3}$, Elena Mancuso ${ }^{4}$, Preetam K. Sharma $^{4}$, Dimitrios A. Lamprou ${ }^{5}$, Romána Zelkó ${ }^{1 *}$

${ }^{1}$ University Pharmacy Department of Pharmacy Administration, Semmelweis University, Hőgyes Endre utca 7-9, H-1092 Budapest, Hungary

${ }^{2}$ Department of Organic Chemistry and Technology, Budapest University of Technology and Economics, Múegyetem rakpart 3, H-1111 Budapest, Hungary

${ }^{3}$ Department of Physical Chemistry and Materials Science, Budapest University of Technology and Economics, Müegyetem rakpart 3, H-1111 Budapest, Hungary

${ }^{4}$ Nanotechnology and Integrated Bio-Engineering Centre (NIBEC), Ulster University, Jordanstown campus, UK

${ }^{5}$ School of Pharmacy, Queen's University Belfast, 97 Lisburn Road, Belfast, BT9 7BL, UK

Corresponding author*: Romána Zelkó, zelko.romana@pharma.semmelweis-univ.hu

\section{ORCID:}

Adrienn Kazsoki: 0000-0002-0611-3124; Attila Farkas: 0000-0002-8877-2587; Diána Balogh-Weiser: 0000-0002-9957-1203; Elena Mancuso: 0000-0003-1742-1656; Preetam K. Sharma: 0000-0002-5694-8445; Dimitrios A. Lamprou 0000-0002-8740-1661; Romána Zelkó: 0000-0002-5419-9137;

\section{Keywords}

coaxial electrospinning, core-shell electrospun fibres, drug delivery, Transmission electron microscopy, Raman spectroscopy

\section{Chemical compounds studied in this article:}

levofloxacin (PubChem CID: 149096); naproxen-sodium (PubChem CID: 23681059); polylactic acid (PubChem CID: 612); polyvinyl pyrrolidone (PubChem CID: 131751496); polysorbate 80 (PubChem CID: 5284448); hydroxypropyl-beta-cyclodextrin (PubChem CID:14049689); chloroform (PubChem CID: 6212); N,N-dimethylformamide (PubChem CID: 6228); ethanol (PubChem CID: 702) 


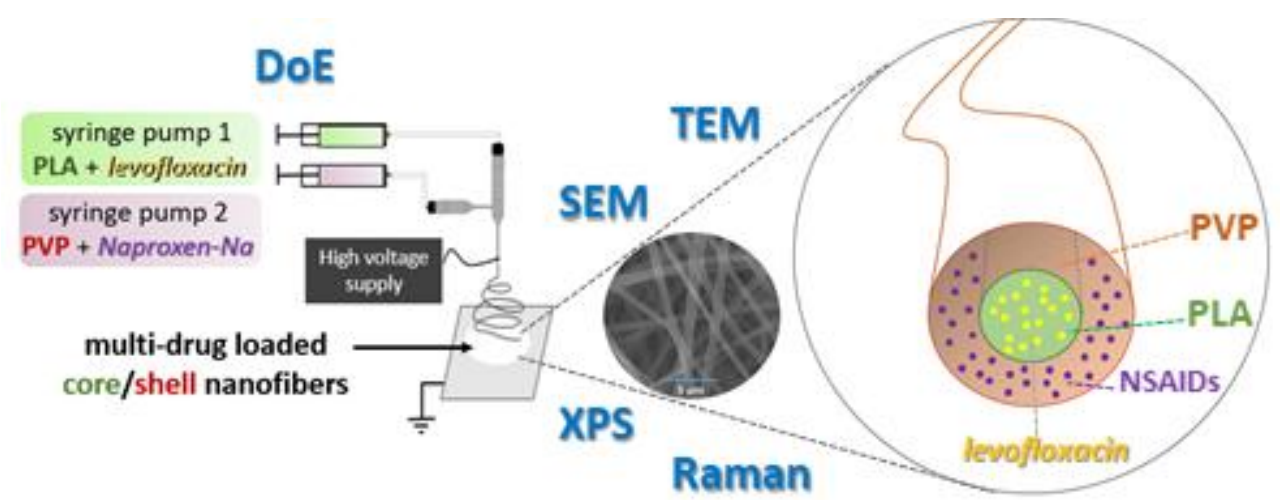

Abstract

In recent years, core-shell nanofibrous drug delivery systems have received increasing attention due to their ability to incorporate two or more active pharmaceutical ingredients (APIs) individually into the desired layer (either core or sheath) and thereby finely tune the release profiles of even incompatible drugs in one system. This study aims to perform formulation and solid-state characterisation of levofloxacin-loaded polylactic acid (PLA) naproxen-sodium-loaded polyvinyl pyrrolidone (PVP) bicomponent core-shell fibrous sheets and examine the electro spinnability of the precursor combinations. The selected drugs have potential therapeutic relevance in similar systems intended for wound healing; however, in this study, they are used as model drugs to understand the physicochemical properties of a drug loaded system. In order to determine the best core- and shell-solution combination, a full factorial experimental design is used. A combination of various morphological (scanning electron microscopy and transmission electron microscopy) and microstructural characterisation techniques (X-ray photoelectron spectroscopy and Raman spectroscopy) was applied to non-invasively obtain information about the structure of the fibres and the embedded drugs. The results indicate that core-shell fibres of different compositions could be successfully prepared with various structural homogeneities. The best core-shell structure was obtained using a combination of $15 \%(\mathrm{w} / \mathrm{w})$ shell concentration and $8 \%(\mathrm{w} / \mathrm{w})$ PLA solution concentration. In addition to the conventional core-shell structural verification methods, the Raman spectroscopy method was implemented to reveal not only the core-shell structure of the PLA/PVP nanofibers but also the form of the embedded drugs. The Raman mapping of the fibres confirm the above results, and it is shown that an amorphous solid dispersion is formed as a result of the coaxial electrospinning process. 


\section{Introduction}

Electrospinning is a well controllable, relatively simple, and cost-effective technique for the preparation of matrices with nano-and micrometre-sized fibres (Pelipenko et al., 2015; Smith and Ma, 2004; Xue et al., 2019). Owing to the unique properties of fibrous materials, such as the high porosity with an interconnected pore network and the large surface area of fibrous sheets, they can be embedded together with active pharmaceutical ingredients (APIs) into a polymeric matrix carrier in an amorphous state. This could lead to increased dissolution, which increases the bioavailability of drugs with lower solubility (Huang et al., 2003).

Nano- and micro fibrous materials have a unique structure, vast material variety, and the potential for multifunction and mass production; therefore, they are widely used with nanofibrous scaffolds, which are loaded with different drugs or drug combinations, as drug delivery systems for tissue engineering and wound bandage (Barnes et al., 2007; Haider et al., 2018). These materials are widely used in biomedical applications as they have similar features and morphologies as that of the extracellular matrix, which is the non-cellular component that is present within all tissues and organs and plays a crucial role in the wound healing process (Liu et al., 2017). Therefore, materials that can mimic their structure and stimulate cell proliferation can help in wound healing (Rieger et al., 2013). Zahra et al. reported that a core-shell structure could provide a more controlled release of a model biocide with prolonged antibacterial properties than single nanofibers. These nanofibrous mats have the potential to selectively release antibacterial agents to prevent wound infections without delaying wound healing (Abdali et al., 2019).

However, the diverse field of applications requires adequate functionality-related characteristics. In order to fulfil the numerous quality and functionality requirements of fibrous scaffolds, a multicomponent core-shell fibrous structure has been developed. It can provide additional unique and essential properties that are relevant for biomedical applications (Elahi et al., 2013). The core polymer/composite ensures features that are required for tissue regeneration. At the same time, the shell material protects the unstable APIs embedded into the core from unfavourable environmental effects. This improves the hydrophilicity and biocompatibility of the fibrous samples (Elahi et al., 2013; Han and Steckl, 2019). One of the significant advantages of these core-shell nanostructures is the ability to tailor the release properties of the incorporated drug, which is easily achieved by the careful choice of the drugpolymer-solvent (or solvent mixture) precursor system (Huang and Thomas, 2018; Jiang et 

al., 2005). Basically, the core-shell fibrous structure provides four directions for improving polymer-based nanofibrous drug delivery systems (Han and Steckl, 2019):

(1) Combining two or more polymers or polymer compositions in a single fibre provides the required biocompatibility and mechanical properties.

(2) By incorporating the drug into the core and covering it with the shell, a sustained release of the drug can be achieved.

(3) Two or more APIs can be incorporated individually into the desired layer (either the core or the sheath), which enables controlled release of the embedded drugs.

(4) Trigger release or external stimuli-responsive controlled release (Han and Steckl, 2019).

Although the basics of the production of core-shell type nanofibers are known in the literature, the development of a new core-shell system is still challenging. Several drug combinations have been incorporated into various polymer-based core-shell fibres; however, a technique for verifying the core-shell structure has not been studied in detail yet. In a few studies, the structure was verified using scanning electron microscopy (SEM) measurements (Huang and Thomas, 2018; Khalf et al., 2015). However, it should be noted that SEM can be a useful tool to verify the core-shell structure of the fibres only if the core component can be selectively extracted (Wang et al., 2010).

The typical and conventional core-shell structure characterisation technique is the use of transmission electron microscopy (TEM), which is capable of detecting materials with different densities. This technique is primarily applicable in cases where different materials are used for the core and shell. However, it is also possible to make a core-shell fibrous sample using the same polymer as core and sheath materials. Nevertheless, this method is less applicable in this case, because the difference in density is rather small as they are caused only by the APIs (Alharbi et al., 2018; Chen et al., 2010; Pakravan et al., 2012; Sun et al., 2003; Zhang et al., 2004).

Atomic force microscopy (AFM) has also been used to verify the structure. However, its applicability depends on the observation of the surface morphologies of single needle electrospun samples and the coaxial electrospun scaffold and even on the mechanomanipulation of the force spectroscopy. Nevertheless, for this measurement, it is essential to have a sample of the sparse surface coverage with minimal overlap between the fibres, and only those parts of the sample that lie completely on the disc can be examined (Chen et al., 2015; Kazsoki et al., 2018; Zander et al., 2011). 
Another novel non-invasive technique is Raman mapping, which can provide structural and quantitative information of the fibres by monitoring selective peaks of the polymers and the APIs (if their concentrations are large enough). This technique is suitable for tracking the physical state of the embedded drugs (Farkas et al., 2015; Sfakis et al., 2017; Sharikova et al., 2020). However, due to its limitations with regard to resolution, it can be used effectively only in the case of fibres with larger diameters (close to or over a micrometre).

This study aims to prepare levofloxacin-loaded polylactic acid (PLA) - naproxen-sodiumloaded poly(vinylpyrrolidone) (PVP) bicomponent core-shell fibrous sheets and examine the electro spinnability of the precursor combinations. The selected APIs have a potential therapeutic relevance in wound healing; however, in this study, these molecules are used as model drugs to understand the physicochemical properties of a drug-loaded core-shell fibre based system. A full factorial experimental design (of two factors in three levels) was used to determine the best combination of the drug-loaded core (PLA) and shell (PVP) viscous solutions for coaxial electrospinning. A combination of conventional (such as TEM and XPS) and novel morphological and solid-state characterisation methods (such as Raman spectroscopy) was applied to simultaneously monitor the core-shell structure and the form of actives embedded into the core and shell polymers. The study investigates the best composition with excellent fibre structure characteristics for potential application in chronic wound healing (Fig. 1).
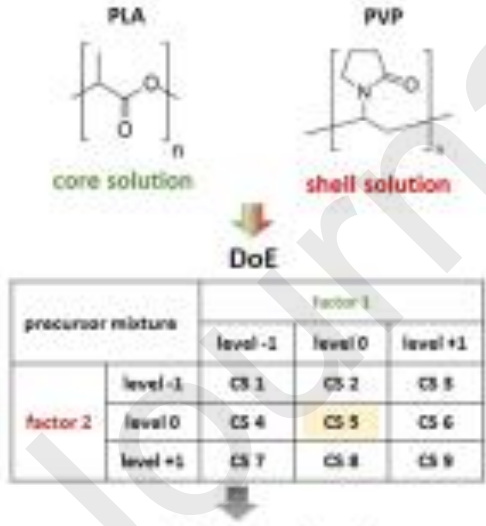

coaxial electrospinning

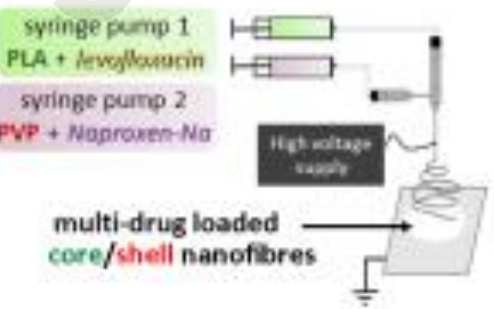

morpholagical characterization

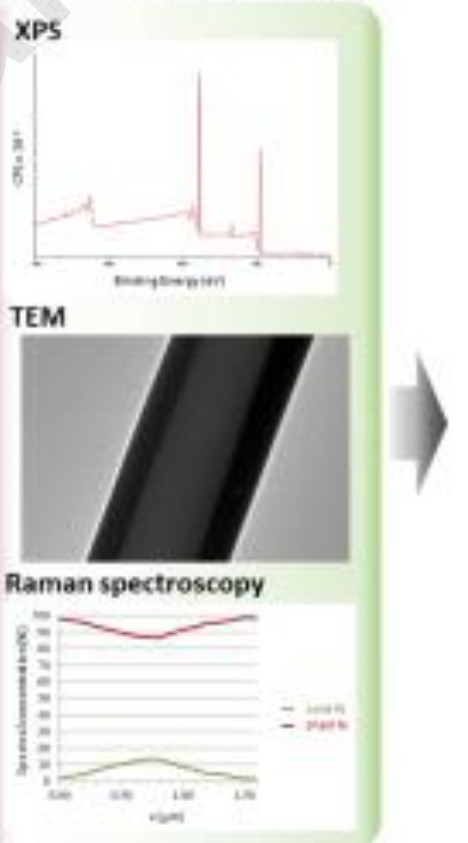

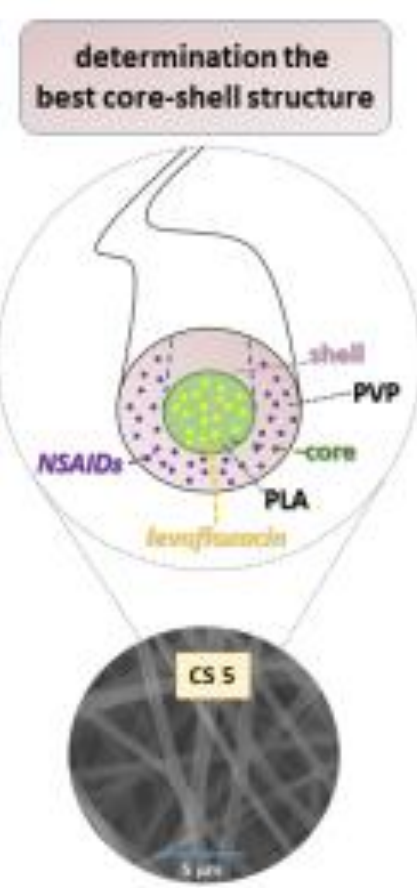




\section{Materials and methods}

\subsection{Materials}

Levofloxacin ((S)-9-fluoro-2,3-dihydro-3-methyl-10-(4-methylpiperazin-1-yl)-7-oxo-7Hpyrido[1,2,3-de]-1,4-benzoxazine-6-carboxylic acid) >98\%, $\mathrm{M=361.37} \mathrm{g} \mathrm{mol}^{-1}$ ) and naproxen-sodium $((S)$-6-Methoxy- $\alpha$-methyl-2-naphthaleneacetic acid sodium salt, $>98 \%, \mathrm{M}=$ $252.24 \mathrm{~g} \mathrm{~mol}^{-1}$ ), which were obtained commercially from Sigma-Aldrich (Budapest, Hungary), were used as the APIs. Polylactic acid (PLA, GF45989881, $\mathrm{M}_{\mathrm{w}} \sim 85000-160000 \mathrm{~g}$ $\mathrm{mol}^{-1}$ nominal granule size of 3-5 mm, density $1.24 \mathrm{~g} \mathrm{~cm}^{-3}$ ) was chosen as the base of the core part of the fibres, and poly(vinyl pyrrolidone) (PVP, Kollidon K90, average $\mathrm{M}_{\mathrm{w}} \sim 1500000 \mathrm{~g}$ $\mathrm{mol}^{-1}$ ) was chosen as the shell polymer; both of them were obtained from Sigma-Aldrich (Budapest, Hungary). Hydroxypropyl-beta-cyclodextrin (average degree of substitution (n) 4.5, $\left.(1135.0+\mathrm{n} * 58.1) \mathrm{g} \mathrm{mol}^{-1}\right)$ was purchased from Cyclolab Ltd. (Budapest, Hungary). Polysorbate 80 was purchased from Molar Chemicals (Budapest, Hungary). Absolute ethanol (Molar Chemicals, Budapest, Hungary) and distilled water were used to prepare the shell electrospinning precursor. As a solvent of the viscous solution of the core, chloroform (anhydrous grade, containing amylenes as stabilisers, >99\%, Sigma Aldrich, Budapest, Hungary) and N,N-dimethylformamide (DMF, anhydrous grade, 99.8\%, Sigma Aldrich, Budapest, Hungary) were used. The materials were used without further purification.

\subsection{Preparation of polymer precursors for electrospinning experiments}

In this study, PLA and PVP were chosen as the polymers for the core and sheath components, respectively.

Since the use of a precursor solution has a significant impact on the success of the electrospinning process and the morphology of the prepared samples, preliminary experiments were performed to determine the optimal composition of the viscous polymer solutions used for the shell and core formation. Therefore, the concentrations of the polymer solutions, applied solvent mixture, and other additives (the polysorbate 80 ) were determined.

Water: ethanol 8:2 (m:m) was used for the shell solution and chloroform: DMF 6:1 (m:m) solvent was used for the core solution. The previous experiment revealed that when the PLA concentration is less than $7 \%(\mathrm{w} / \mathrm{w})$, single-needle electrospinning does not result in beadfree, continuous fibres.

Naproxen-sodium-loaded PVP solutions and levofloxacin-loaded PLA solutions were prepared by using the appropriate composition and solvent mixture under magnetic stirring until a clear, viscous solution was obtained. Both the core and sheath solutions contained 
$0.5 \%(\mathrm{w} / \mathrm{w})$ polysorbate 80 . The sheath solutions contained $2 \%(\mathrm{w} / \mathrm{w})$ non-steroidal antiinflammatory drug and 14\% (w/w) HP- $\beta-C D$. The levofloxacin concentration of the core solution was adjusted to $0.5 \%(\mathrm{w} / \mathrm{w})$.

A full factorial design of the experiment was used to optimise the fibre composition. The two factors were the core- and shell-polymer solution concentrations, and each factor was examined at three levels. Only the polymer concentration differed between the solutions. Based on the preliminary single-needle electrospinning experiments, the PLA concentration (factor 1) was chosen as 7\%, 8\%, and 9\% (w/w), while the PVP concentration (factor 2) was chosen as 14\%, 15\%, and 16\% (w/w) (Table 1).

Table 1 Design of experiments (DoE) indicating the various electrospun samples

\begin{tabular}{|l|l|l|l|l|}
\hline \multicolumn{2}{|c|}{ sample } & \multicolumn{3}{c|}{ factor 1 } \\
\cline { 3 - 5 } \multicolumn{2}{|c|}{ factor 2 } & level-1 & level 0 & level +1 \\
\hline & level -1 & CS_1 & CS_2 & CS_3 \\
\cline { 2 - 5 } & level 0 & CS_4 & CS_5 & CS_6 \\
\cline { 2 - 5 } & level +1 & CS_7 & CS_8 & CS_9 \\
\hline
\end{tabular}

\subsection{Coaxial electrospinning}

A lab-scale coaxial electrospinning equipment (SpinSplit Ltd., Budapest, Hungary) was used for preparing the fibre. Homogenous precursor solutions were placed in plastic syringes (Luer lock syringe, Sigma Aldrich Ltd., Budapest, Hungary), which were connected to conventional (22 gauge) or coaxial (inner needle: 22 gauge and outer needle: 18 gauge) emitters using Teflon tubing. Pump systems were used to provide a continuous feeding rate, which was 0.08 $\mu 1 / \mathrm{s}$ for the core solution and $0.2 \mu \mathrm{l} / \mathrm{s}$ for the shell solution. The applied voltage was $10-25$ $\mathrm{kV}$, and the emitter to collector distance was set between $10-20 \mathrm{~cm}$. Finally, the best fibre characteristic was achieved when the applied voltage was $15 \pm 0.5 \mathrm{kV}$ and the emitter to collector distance was $20 \mathrm{~cm}$.

The samples were collected on a grounded aluminium plate covered with aluminium foil. During the electrospinning process, the formation of Taylor cone and its stability were monitored using the camera system of the equipment. This helped in identifying the best process parameters. The electrospinning experiments were performed in a well-controlled room having an ambient temperature of $22 \pm 1{ }^{\circ} \mathrm{C}$ and a relative humidity of $50 \pm 5 \%$.

\subsection{Scanning electron microscopy (SEM)}

The samples were fixed using a conductive double-sided carbon adhesive tape and then coated with a gold layer (JEOL JFC-1200 Fine Coater, JEOL Ltd., Tokyo, Japan). SEM 
images were taken with a JEOL JSM-6380LA scanning electron microscope (JEOL Ltd., Tokyo, Japan). The acceleration voltage and the working distance were $15 \mathrm{kV}$ and $10 \mathrm{~mm}$, respectively.

\subsection{Transmission Electron Microscopy (TEM)}

The core-shell structure of the coaxially electrospun nanofibers were examined on a JEOL JEM-2100F transmission electron microscope operated at $200 \mathrm{kV}$. The samples for the TEM analysis were prepared by directly depositing the as-spun nanofibers on a carbon grid (Agar Scientific) followed by fixing with a methanol drop. The TEM images were recorded using a charge-coupled device (CCD) camera controlled via Gatan DigitalMicrograph ${ }^{\circledR}$ software.

\subsection{X-ray Photoelectron Spectroscopy (XPS)}

In order to determine the chemical composition of the surface of the samples $(<5-10 \mathrm{~nm})$, XPS measurements were carried out using a Kratos Axis Ultra instrument with an $\mathrm{Al} \mathrm{K}_{\alpha 1} \mathrm{X}$ ray source $(h v=1486.7 \mathrm{eV})$. Core-shell fibres, which were electrospun onto an aluminium foil, were used for the XPS analysis. Wide energy survey scans (WESS) were performed for samples over a binding energy of $0-1205 \mathrm{eV}$ and pass energy of $160 \mathrm{kV}$.

Using the survey-scan spectrum, the surface elemental compositions relative to carbon was calculated from the peak area with a correction for atomic sensitivity. The XPS spectra were analysed using CasaXPS software. The quantification peaks were fitted using the mixed Gaussian-Lorentzian (GL30) function after performing Shirley background correction.

\subsection{Raman microscopy measurements}

The Raman spectroscopy measurements were carried out using a LabRAM system (Horiba Jobin-Yvon, Lyon, France) coupled with an Olympus BX-40 optical microscope (Olympus, Hamburg, Germany) and a $532 \mathrm{~nm} \mathrm{Nd:YAG} \mathrm{laser} \mathrm{source} \mathrm{(Sacher} \mathrm{Lasertechnik,} \mathrm{Marburg,}$ Germany). For optical imaging, objectives of 20x and 100x magnifications were used.

A monochromator and a CCD detector were used for the dispersion and detection of Raman photons, and an intensity filter $(\mathrm{D}=0.3)$ was applied during the measurements. The data was collected and processed using Labspec 5 software.

During the measurements of the reference samples (active pharmaceutical ingredients, polymers, cyclodextrin, and polysorbate), the 20x objective was used. First, the spectra were collected over a comprehensive spectral range of $100-2000 \mathrm{~cm}^{-1}$, so that the spectral range where most of the relevant signals of the fibrous samples are detected can be selected later 
during the final measurement. Finally, the spectral range of $346-1790 \mathrm{~cm}^{-1}$ was selected as the most suitable range for data acquisition, and for this, an optical grating of 1800 groove $/ \mathrm{mm}$ was set to $1100 \mathrm{~cm}^{-1}$. The resolution was $5 \mathrm{~cm}^{-1}$. For some components, fluorescence interference with different levels were observed, and they were removed by baseline correction.

Considerable differences were observed between the Raman activities of the individual components. In the case of the crystalline drugs, an acquisition time of $2 \mathrm{~s}$ was sufficient to achieve intensities of ten thousand times, while $8-30 \mathrm{~s}$ was required for the excipients to provide an excellent signal to noise ratio. For the measurements of the fibrous sample, the 100x objective was used.

Single fibres were suitable for the Raman analysis; the different nanofibrous samples (placebo- and drug-loaded fibres) were electrospun for $3-4 \mathrm{~s}$ on a glass microscope slide covered by an aluminium foil. These samples were investigated without any further sample preparation.

For the spatial distribution measurements, vertical fibres in the Y direction were chosen. They were monitored by systematically moving the motorised stage along the $\mathrm{X}$ direction. Each map was collected with a step size of $0.1 \mu \mathrm{m}$. For the evaluation, the spectra of the placebo and drug-loaded fibres prepared by single-needle electrospinning were used.

The mapped spectra as well as the reference spectra were corrected by fitting the linear baseline through specified points; all the spectra were normalised in terms of the area.

\section{Results and discussion}

\subsection{Morphological characterisation}

SEM was used to investigate the morphology of the sample prepared by coaxial electrospinning. SEM images of the electrospun samples show that randomly oriented fibrous structures without beads and film-like elements having submicron fibre diameter were obtained (Fig. 2). There were no significant differences between the densities of the fibres in case of the core-shell fibrous samples electrospun from different precursor combinations. 

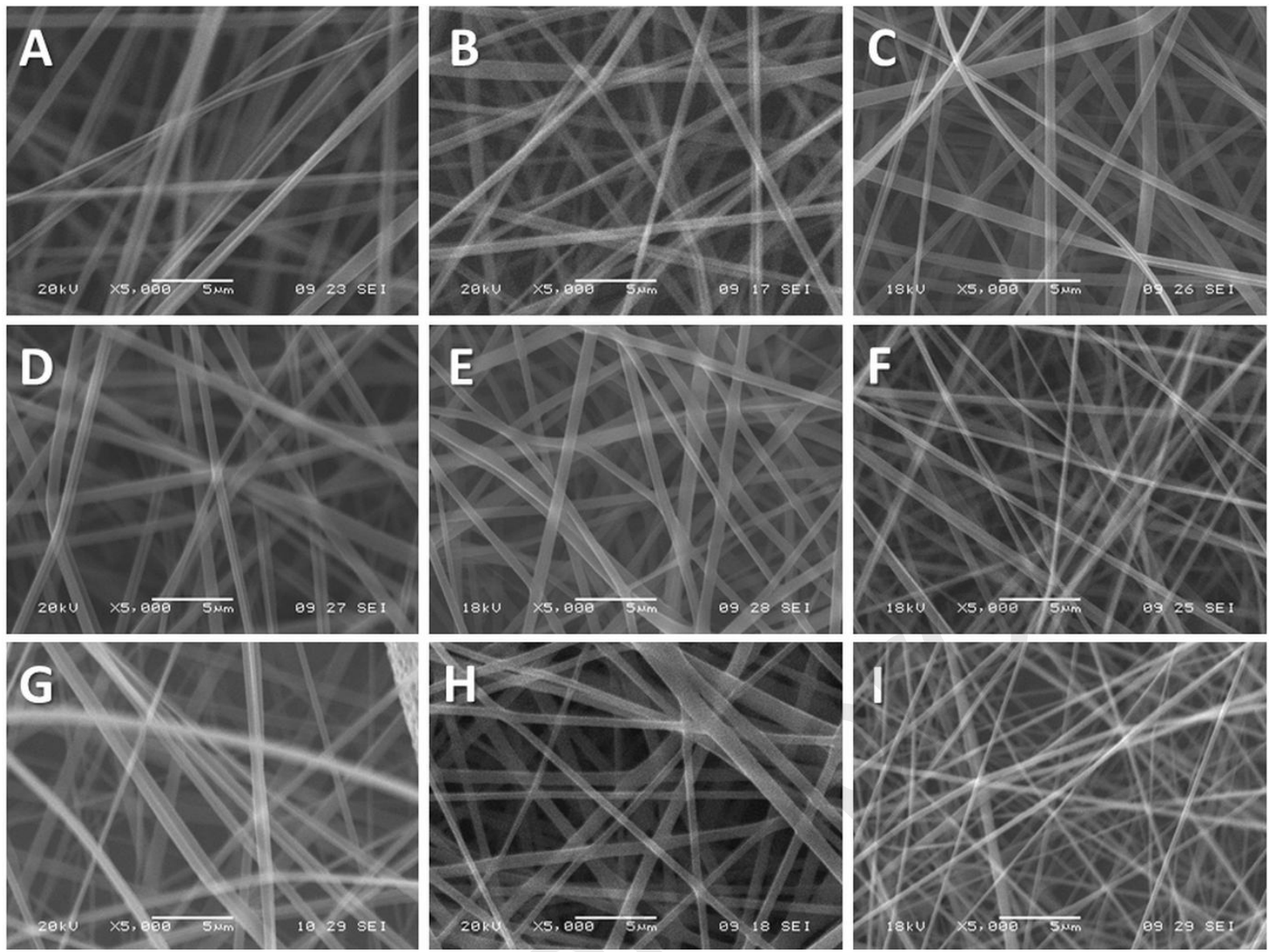

Fig. 2 SEM images of coaxially electrospun samples:

CS_1 (A), CS_2 (B), CS_3 (C), CS_4 (D), CS_5 (E), CS_6 (F), CS_7 (G), CS_8 (H), and

\subsection{Structural investigation}

The core-shell structure of the electrospun samples was investigated via TEM measurements.

Fig. 3 shows the TEM micrographs of the core-shell structure of the composite ultrafine fibres. It was found that for the samples coded CS_4, CS_5, CS_6, and CS_7 (shown in Fig. 3 $\mathbf{D}, \mathbf{E}, \mathbf{F}$, and $\mathbf{G}$, respectively), the diameter of the core structure was uniform throughout the fibre, evidencing a sharp core-shell interface for all the samples analysed. According to previous studies, this implies that the core and shell materials have different electron transmission abilities (Zhang et al., 2006). In addition, the sharp boundaries are associated with the fast processing characteristic of electrospinning, which prevents mixing between the core solution and shell solution (Chen et al., 2010; Sun et al., 2006). For the samples based on 14\% PVP and 16\% PVP with a core concentration of $8 \%$ and 9\% PLA, the core-shell structure was irregular, with an evident effect on the resulting fibre morphology (Fig. 3 A, B, $\mathbf{C}, \mathbf{H}$, and I). This could be attributed to the fact that the core fluid jetting out of coaxial 
capillaries might be split into a number of sub-jets during the electrospinning process (Xue et al., 2019).

297
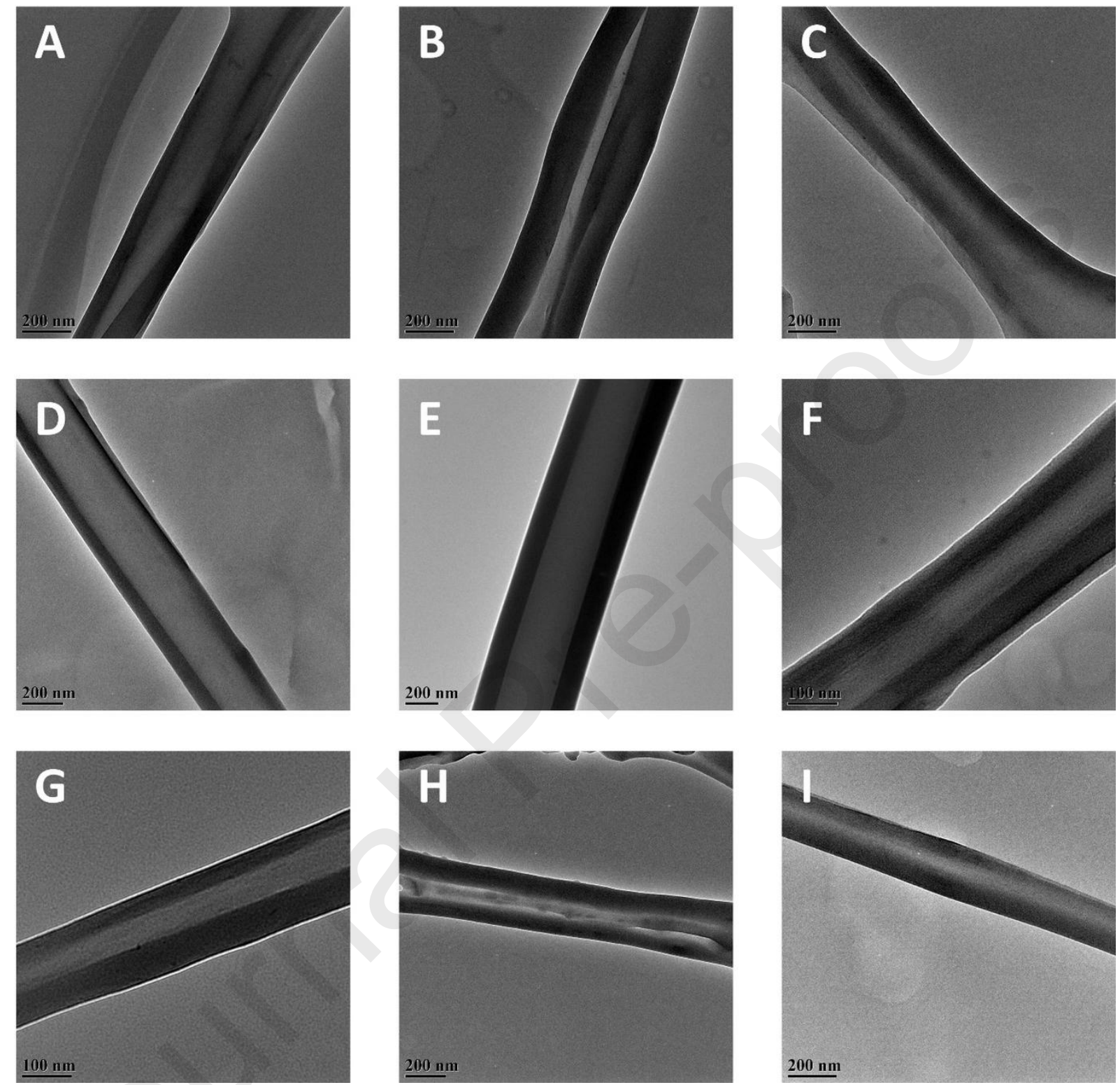

Fig. 3 TEM images of coaxially electrospun samples: CS_1 (A), CS_2 (B), CS_3 (C), CS_4 (D), CS_5 (E), CS_6 (F), CS_7 (G), CS_8 (H), and

\subsection{Surface characterisation of the fibrous samples}

The elemental composition on the surface of the PVP/PLA core-shell electrospun nanofiber was characterised via XPS. Fig. 4 shows the WESS from all the core-shell samples. As expected, the coaxial electrospun meshes showed very similar spectra across different samples; they were characterised by four peaks corresponding to $\mathrm{C} 1 \mathrm{~s}$ (binding energy: 286 
eV), N1s (binding energy: $400 \mathrm{eV}$ ), O1s (binding energy: $532 \mathrm{eV}$ ), and Na1s (binding energy: $1072 \mathrm{eV})$. This suggests consistent composition of the shell in all the samples. Moreover, the XPS data does not show any $\mathrm{F}$ and $\mathrm{Cl}$ signal on the PVP nanofiber surface. Since XPS elemental analysis can detect the characteristics of a specimen at a maximum depth of $\sim 100 \AA$ (Sun et al., 2002), the absence of $\mathrm{F} 1 \mathrm{~s}$ and $\mathrm{Cl} 2 \mathrm{p}$ peaks on the XPS spectra of the nanofiber surfaces indicates the following:

i) The shell thickness is at least beyond the ultimate detection depth of XPS (i.e., 5 $10 \mathrm{~nm})$.

ii) There is good interfacial stability between the inner and outer solutions.

iii) The electrospinning process is effective (Sun et al., 2002).
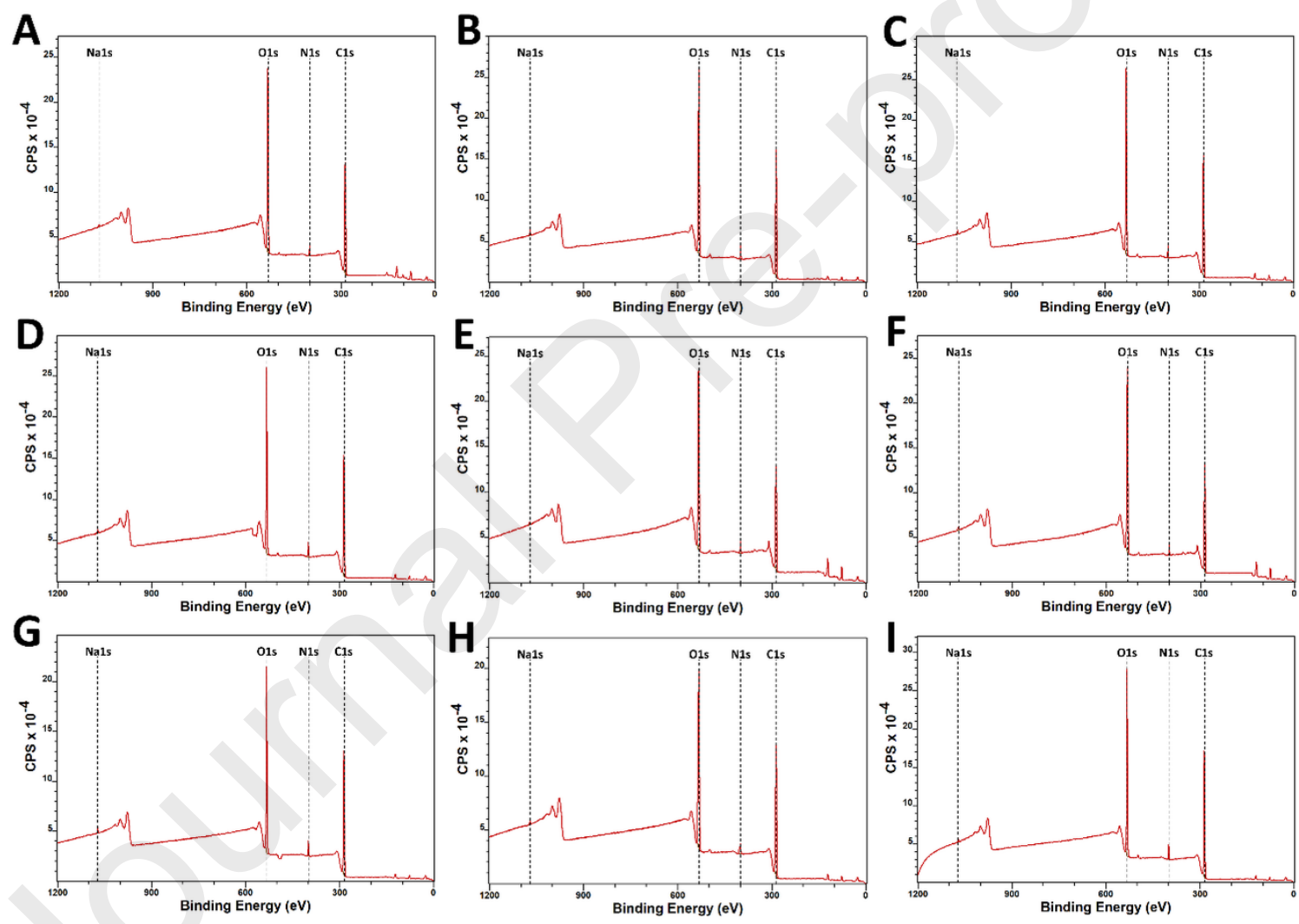

Fig. 4 XPS survey scan spectra from the coaxially produced nanofiber samples: CS_1 (A), CS_2 (B), CS_3 (C), CS_4 (D), CS_5 (E), CS_6 (F), CS_7 (G), CS_8 (H), and CS_9 (I) in the $0-1200 \mathrm{eV}$ range

\subsection{Raman mapping}

Besides the verification of the desired structure, investigation of the physical state of the embedded drugs has a significant impact on the drug delivery system, because it affects the 
drug release as well as the short- and long-term stability of the final dosage. Raman mapping is a useful method for analysing these. Based on the TEM results, the three best compositions were selected for further analysis using Raman spectroscopy, in which the effect of factor 1 is examined.

Fig. 5 shows the Raman spectra of the active pharmaceutical ingredients, namely the placeboand drug-loaded samples. Although in the case of the fibrous samples, lower intensities could be observed compared to the initial materials, the recorded spectra of the fibrous samples did not differ considerably, which suggests that the fibre formations had little influence on the shape of the spectra of the polymers.

It can be seen that there is a small difference between the spectra of the crystalline drugs and the drug-loaded fibres. In the latter case, fewer and weaker drug signals could be observed. The broadening and merging of the spectra could be related to the fact that the drugs were incorporated into the fibres in an amorphous state. In the case of the levofloxacin-loaded fibrous sample, the most visible changes in the peak can be observed at 496, 518, 1555, 1621, and $1658 \mathrm{~cm}^{-1}$, while naproxen made significant contributions to the signals of the polymeric carrier at $523,750,1389,1486,1581$, and $1634 \mathrm{~cm}^{-1}$.
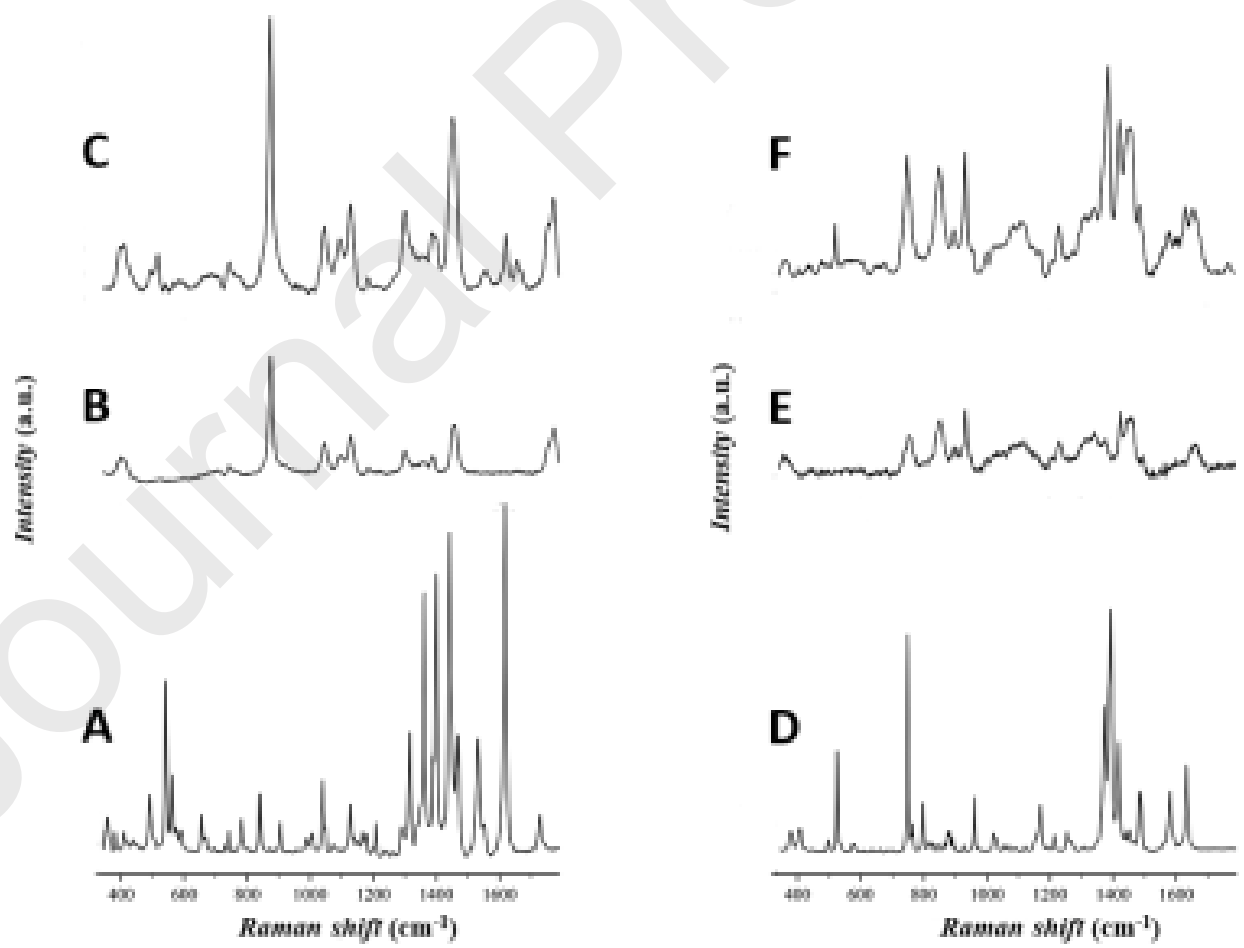

Fig. 5 Raman spectra of the model drugs, namely the placebo- and drug-loaded core- and shell nanofibers prepared by single-needle electrospinning: levofloxacin (A), placebo core nanofiber (B), levofloxacin-loaded core nanofiber (C), naproxen-Na (D), placebo shell nanofiber (E), and naproxen-Na-loaded shell nanofiber 
349 A novel Raman mapping method was used to confirm the core-shell structure by monitoring 350 selected polymer signals of the spectra. For the evaluation, single core and shell fibre 351 reference spectra were used, and the spectral concentrations were calculated using the 352 classical least squares (CLS) method with a spectral range of $346-1790 \mathrm{~cm}^{-1}$.

353 The Raman maps show the contributions of the polymer components in the fibres (Fig. 6). 354 The spectral concentration of the polymer components was normalised to $100 \%$. The green 355 represents the spectral concentration of the core polymer (PLA), while the red line represents 356 that of the shell polymer (PVP).

357 The signals from the edge of the fibre came only from the shell polymer, while the signals 358 from the centre part (of the 2D projection of the fibre) included contributions from both the 359 polymers, which is indicative of the core-shell structure of a single coaxially electrospun 360 fibre. This is consistent with the results of other structural investigation methods. 

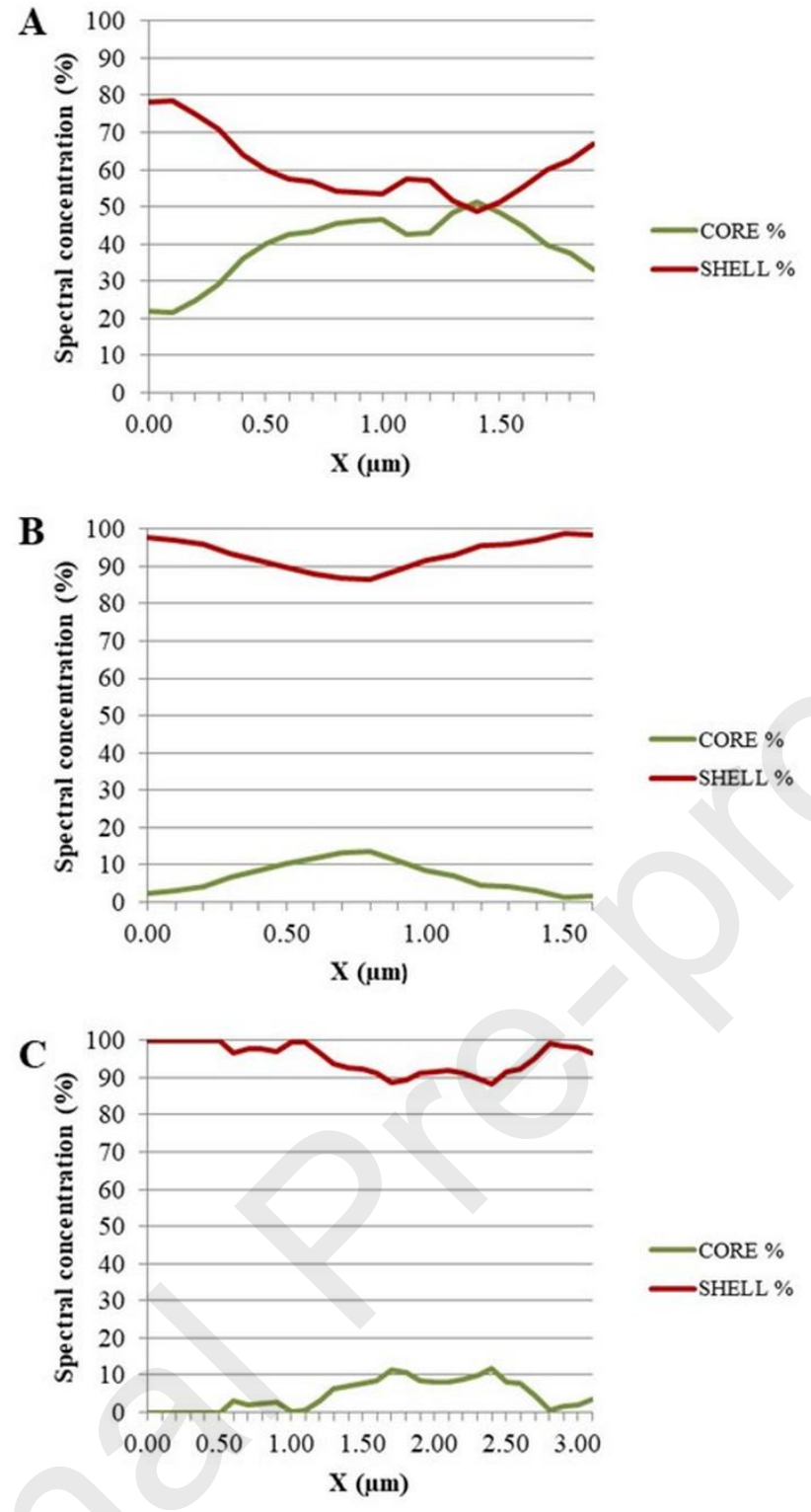

Fig. 6 Raman spectra from the core-shell fibrous samples

(A:CS_4, B: CS_5, C:CS_6)

\section{Conclusion}

366 Levofloxacin-loaded polylactic acid (PLA) - naproxen-sodium-loaded poly(vinylpyrrolidone) (PVP) bicomponent core-shell fibrous sheets were formed from precursors of different concentrations according to a full factorial DoE to optimise the fibre composition. The SEM measurements indicated that each of the nine examined core-shell precursor combinations enabled the formation of clear fibrous mats. The conventional fibre-structure characterisation (e.g. TEM) indicated that core-shell fibres of different compositions were successfully

372 prepared with various structural homogeneities. The XPS spectra of the nanofiber surfaces 373 indicated excellent interfacial stability between the inner and outer polymer solutions. The 
best sample was achieved with the combination of $15 \%(\mathrm{w} / \mathrm{w})$ shell concentration and $8 \%$ (w/w) PLA solution concentration. In addition to the conventional core-shell structural verification methods, the Raman spectroscopy method was successfully applied to reveal the core-shell structure of the PLA/PVP nanofibers. The spatial distributions of the polymers were found to be different for different sampling points. In addition, the formation of amorphous solid dispersions was observed.

Core-shell fibrous materials have been successfully prepared in various studies using numerous polymer combinations; however, there is no universal morphological characterisation method for structure verification. With regard to the characterisation of the structure of coaxially electrospun samples, it is very important to consider the properties of the polymers used when selecting the characterisation method. A combination of several methods may be required to obtain information about the structure. Although it has certain limitations, Raman mapping could be a universal method for fibre structure determination, especially since it can obtain information about the distribution of the drug when the concentration of the embedded drugs in the fibre is large. This could be the subject of future research.

\section{Declarations}

\subsection{Funding}

This project was supported by ÚNKP-19-3-I New National Excellence Program of the Ministry for Innovation and Technology.

\subsection{Conflict of interest disclosure}

The authors declare no conflict of interest.

\subsection{Availability of data and material}

Not applicable.

\subsection{Code availability}

Not applicable.

\subsection{Authors' Contributions}

Adrienn Kazsoki designed the experiments, prepared the viscous solution, formulated the electrospun fibrous mats, analysed and evaluated the measurements, and wrote the manuscript. Attila Farkas performed and evaluated the Raman spectroscopy measurements. Elena Mancuso, Preetam K. Sharma, and Dimitrios A. Lamprou performed the TEM and XPS measurements and analysis. Diána Balogh-Weiser performed the SEM measurements. Romána Zelkó finalised the manuscript. 


\section{References}

Abdali, Z., Logsetty, S., Liu, S., 2019. Bacteria-Responsive Single and Core-Shell Nanofibrous Membranes Based on Polycaprolactone/Poly(ethylene succinate) for OnDemand Release of Biocides. ACS Omega 4, 4063-4070.

Alharbi, H.F., Luqman, M., Khalil, K.A., Elnakady, Y.A., Abd-Elkader, O.H., Rady, A.M., Alharthi, N.H., Karim, M.R., 2018. Fabrication of core-shell structured nanofibers of poly (lactic acid) and poly (vinyl alcohol) by coaxial electrospinning for tissue engineering. European Polymer Journal 98, 483-491.

Barnes, C.P., Sell, S.A., Boland, E.D., Simpson, D.G., Bowlin, G.L., 2007. Nanofiber technology: Designing the next generation of tissue engineering scaffolds. Advanced Drug Delivery Reviews 59, 1413-1433.

Chen, R., Huang, C., Ke, Q., He, C., Wang, H., Mo, X., 2010. Preparation and characterization of coaxial electrospun thermoplastic polyurethane/collagen compound nanofibers for tissue engineering applications. Colloids and Surfaces B: Biointerfaces 79, 315-325.

Chen, Y., Qian, C., Miao, N., 2015. Atomic force microscopy indentation to determine mechanical property for polystyrene-silica core-shell hybrid particles with controlled shell thickness. Thin Solid Films 579, 57-63.

Elahi, M.F., Lu, W., Guopling, G., Khan, F., 2013. Core-shell Fibers for Biomedical Applications- A Review. Journal of Bioengineering \& Biomedical Science.

Farkas, A., Vajna, B., Sóti, P.L., Nagy, Z.K., Pataki, H., Van der Gucht, F., Marosi, G., 2015. Comparison of multivariate linear regression methods in micro-Raman spectrometric quantitative characterization. Journal of Raman Spectroscopy 46, 566-576.

Haider, A., Haider, S., Kang, I.-K., 2018. A comprehensive review summarizing the effect of electrospinning parameters and potential applications of nanofibers in biomedical and biotechnology. Arabian Journal of Chemistry 11, 1165-1188.

Han, D., Steckl, A.J., 2019. Coaxial Electrospinning Formation of Complex Polymer Fibers and their Applications. ChemPlusChem 84, 1453-1497.

Huang, C., Thomas, N.L., 2018. Fabricating porous poly(lactic acid) fibres via electrospinning. European Polymer Journal 99, 464-476.

Huang, Z.-M., Zhang, Y.Z., Kotaki, M., Ramakrishna, S., 2003. A review on polymer nanofibers by electrospinning and their applications in nanocomposites. Composites Science and Technology 63, 2223-2253.

Jiang, H., Hu, Y., Li, Y., Zhao, P., Zhu, K., Chen, W., 2005. A facile technique to prepare biodegradable coaxial electrospun nanofibers for controlled release of bioactive agents. Journal of Controlled Release 108, 237-243.

Kazsoki, A., Szabó, P., Domján, A., Balázs, A., Bozó, T., Kellermayer, M., Farkas, A., Balogh-Weiser, D., Pinke, B., Darcsi, A., Béni, S., Madarász, J., Szente, L., Zelkó, R., 2018. 
Microstructural Distinction of Electrospun Nanofibrous Drug Delivery Systems Formulated with Different Excipients. Molecular Pharmaceutics 15, 4214-4225.

Khalf, A., Singarapu, K., Madihally, S.V., 2015. Cellulose acetate core-shell structured electrospun fiber: fabrication and characterization. Cellulose 22, 1389-1400.

Liu, M., Duan, X.-P., Li, Y.-M., Yang, D.-P., Long, Y.-Z., 2017. Electrospun nanofibers for wound healing. Materials Science and Engineering: C 76, 1413-1423.

Pakravan, M., Heuzey, M.-C., Ajji, A., 2012. Core-Shell Structured PEO-Chitosan Nanofibers by Coaxial Electrospinning. Biomacromolecules 13, 412-421.

Pelipenko, J., Kocbek, P., Kristl, J., 2015. Critical attributes of nanofibers: Preparation, drug loading, and tissue regeneration. International Journal of Pharmaceutics 484, 57-74.

Rieger, K.A., Birch, N.P., Schiffman, J.D., 2013. Designing electrospun nanofiber mats to promote wound healing - a review. Journal of Materials Chemistry B 1, 4531-4541.

Sfakis, L., Sharikova, A., Tuschel, D., Costa, F.X., Larsen, M., Khmaladze, A., Castracane, J., 2017. Core/shell nanofiber characterization by Raman scanning microscopy. Biomed. Opt. Express 8, 1025-1035.

Sharikova, A., Foraida, Z.I., Sfakis, L., Peerzada, L., Larsen, M., Castracane, J., Khmaladze, A., 2020. Characterization of nanofibers for tissue engineering: Chemical mapping by Confocal Raman microscopy. Spectrochimica Acta Part A: Molecular and Biomolecular Spectroscopy 227, 117670 .

Smith, L.A., Ma, P.X., 2004. Nano-fibrous scaffolds for tissue engineering. Colloids and Surfaces B: Biointerfaces 39, 125-131.

Sun, B., Duan, B., Yuan, X., 2006. Preparation of core/shell PVP/PLA ultrafine fibers by coaxial electrospinning. Journal of Applied Polymer Science 102, 39-45.

Sun, Y., Yin, Y., Mayers, B.T., Herricks, T., Xia, Y., 2002. Uniform Silver Nanowires Synthesis by Reducing AgNO3 with Ethylene Glycol in the Presence of Seeds and Poly(Vinyl Pyrrolidone). Chemistry of Materials 14, 4736-4745.

Sun, Z., Zussman, E., Yarin, A.L., Wendorff, J.H., Greiner, A., 2003. Compound Core-Shell Polymer Nanofibers by Co-Electrospinning. Advanced Materials 15, 1929-1932.

Wang, C., Yan, K.-W., Lin, Y.-D., Hsieh, P.C.H., 2010. Biodegradable Core/Shell Fibers by Coaxial Electrospinning: Processing, Fiber Characterization, and Its Application in Sustained Drug Release. Macromolecules 43, 6389-6397.

Xue, J., Wu, T., Dai, Y., Xia, Y., 2019. Electrospinning and Electrospun Nanofibers: Methods, Materials, and Applications. Chemical Reviews 119, 5298-5415.

Zander, N.E., Strawhecker, K.E., Orlicki, J.A., Rawlett, A.M., Beebe, T.P., 2011. Coaxial Electrospun Poly(methyl methacrylate)-Polyacrylonitrile Nanofibers: Atomic Force 
518

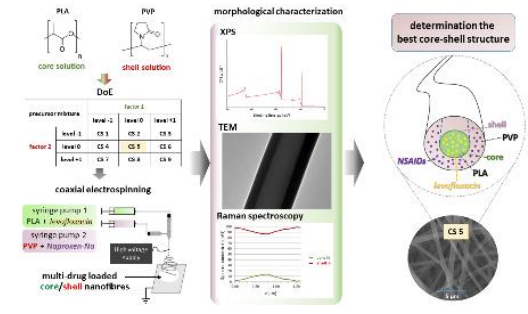
1049-1057.
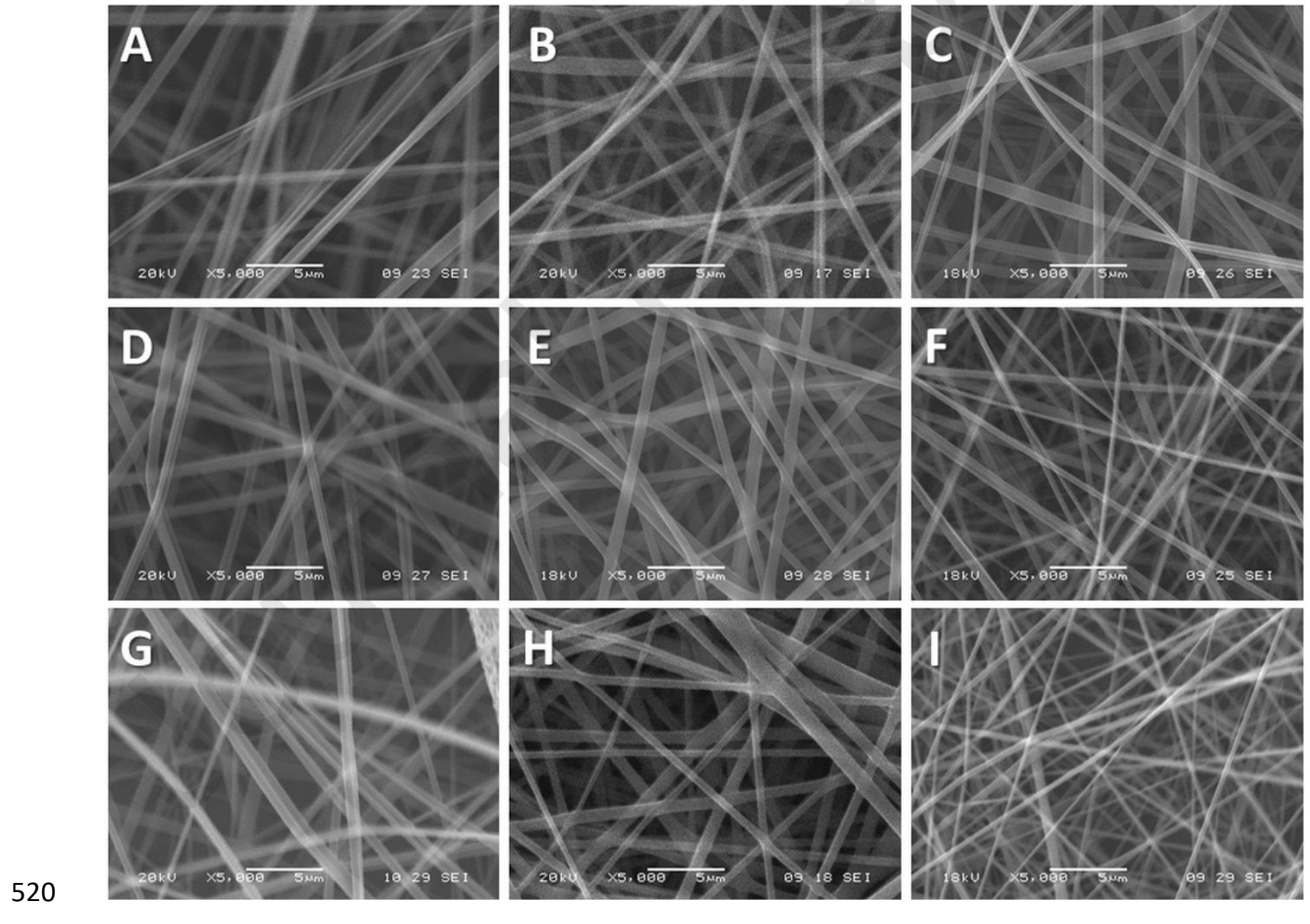

Microscopy and Compositional Characterization. The Journal of Physical Chemistry B 115,

Zhang, Y., Huang, Z.-M., Xu, X., Lim, C.T., Ramakrishna, S., 2004. Preparation of Core-Shell Structured PCL-r-Gelatin Bi-Component Nanofibers by Coaxial Electrospinning.

Zhang, Y.Z., Wang, X., Feng, Y., Li, J., Lim, C.T., Ramakrishna, S., 2006. Coaxial Electrospinning of (Fluorescein Isothiocyanate-Conjugated Bovine Serum Albumin)Encapsulated Poly(e-caprolactone) Nanofibers for Sustained Release. Biomacromolecules 7,

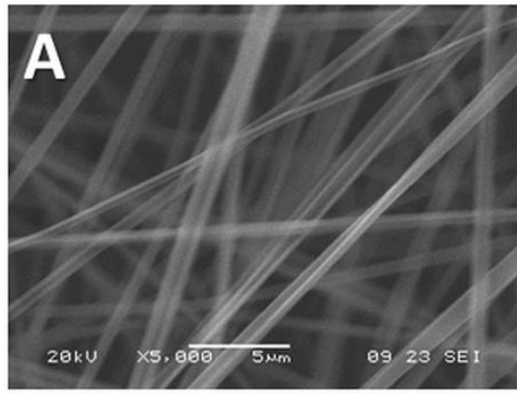




\section{Journal Pre-proofs}
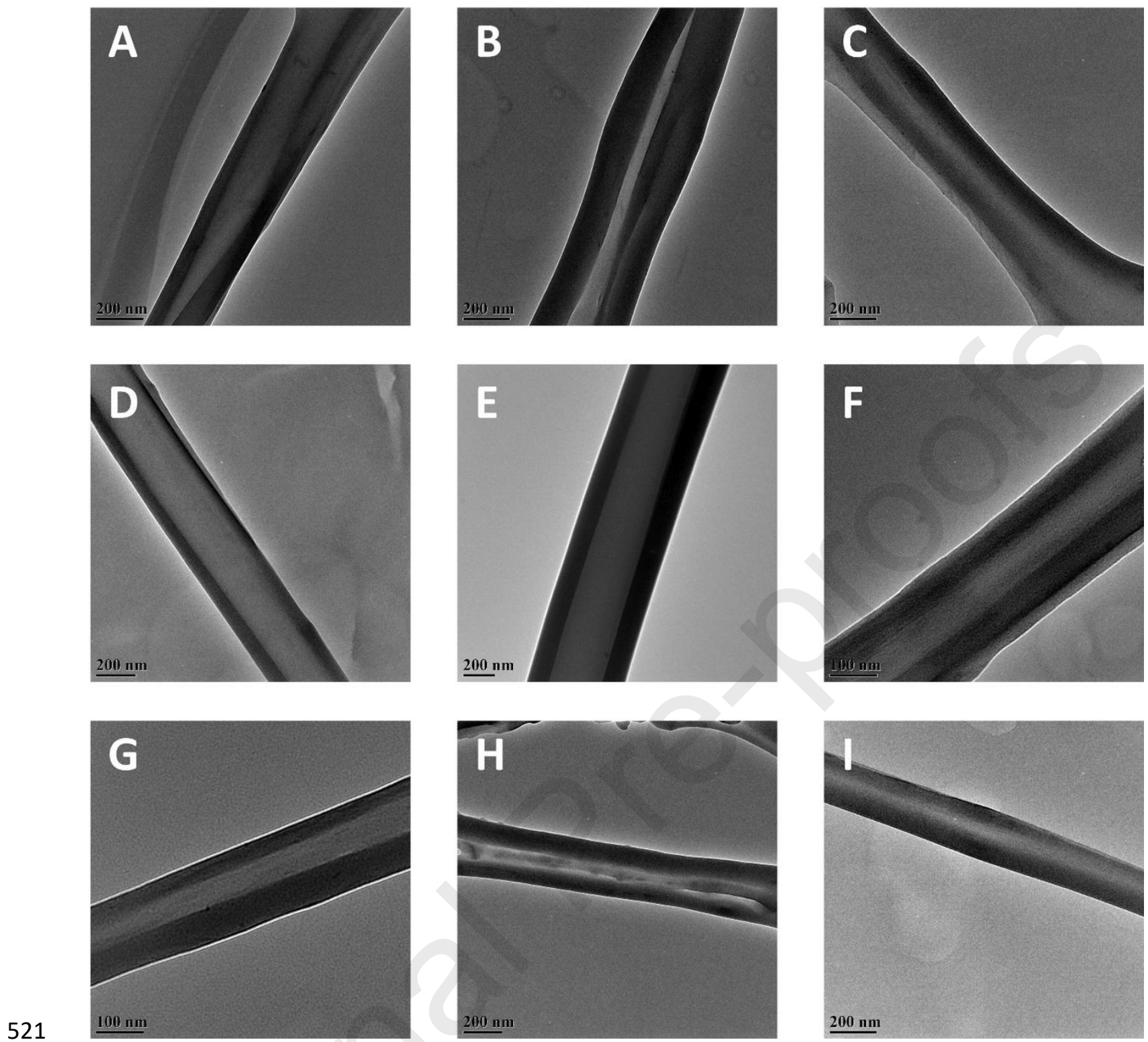

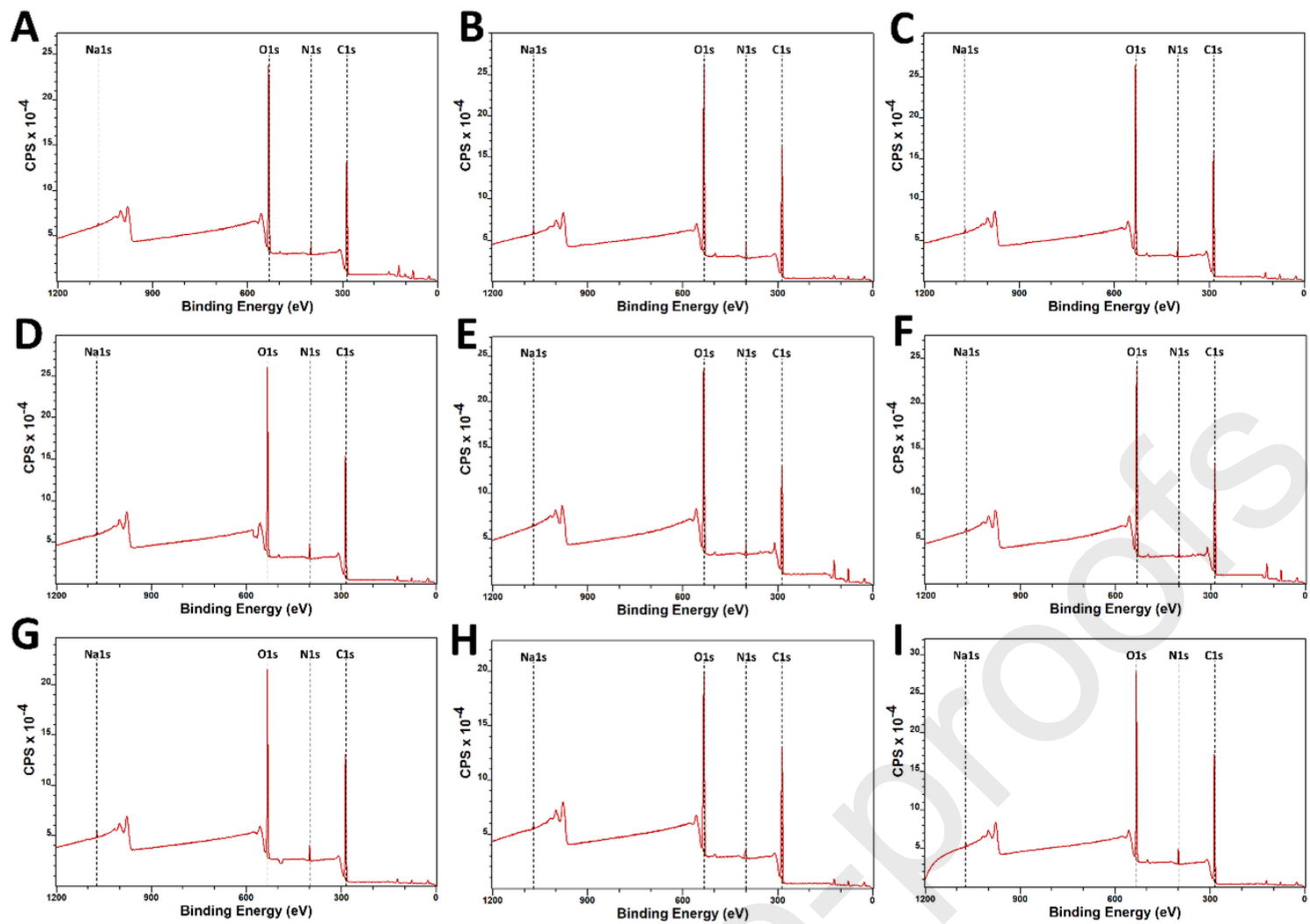

522

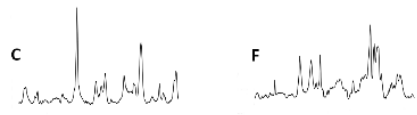

I B Daw

523

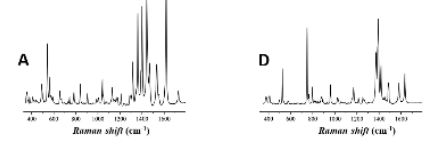



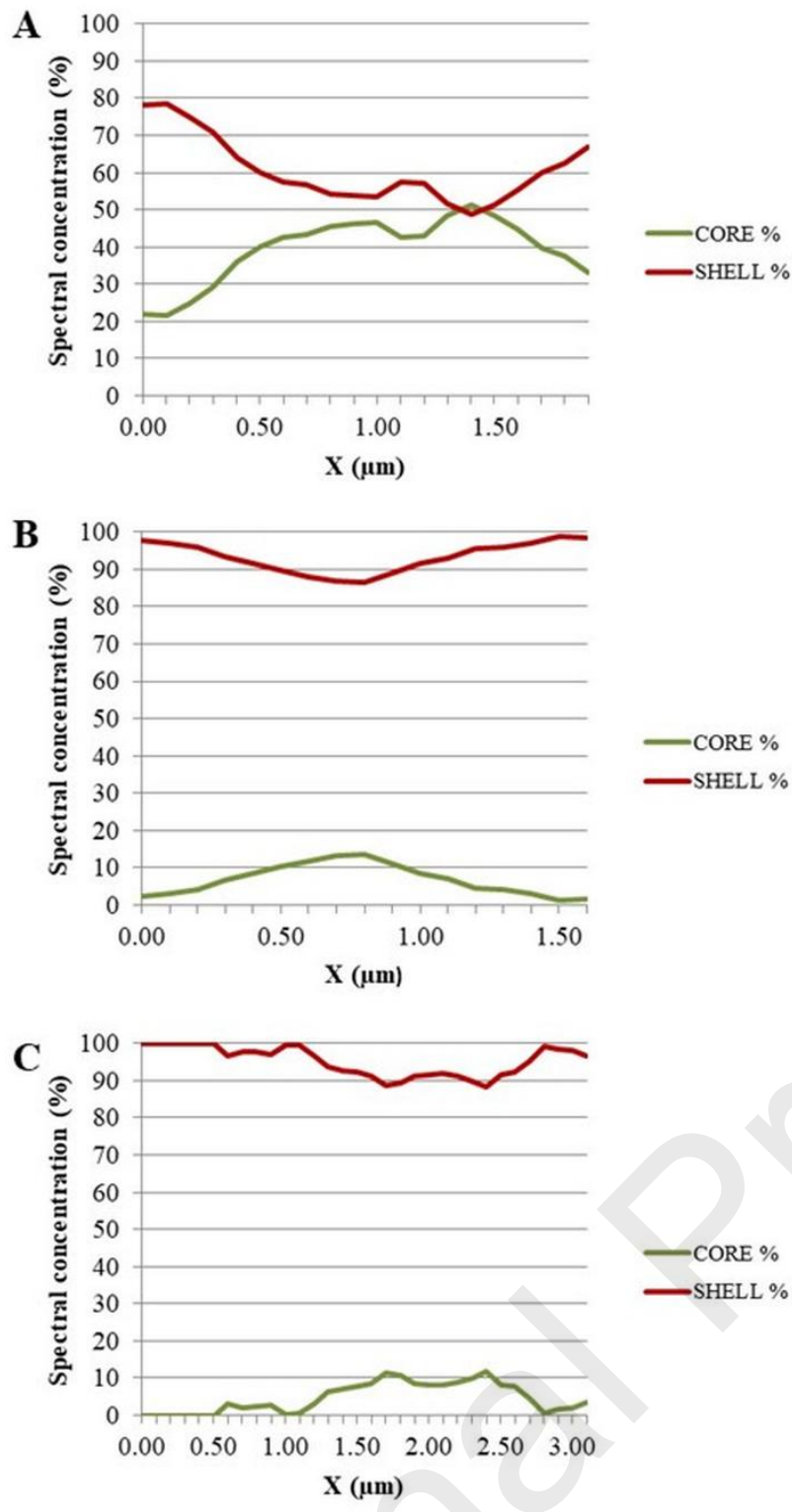

\begin{tabular}{|l|l|l|l|l|}
\hline \multicolumn{2}{|c|}{ sample } & \multicolumn{3}{c|}{ factor 1 } \\
\cline { 3 - 5 } \multicolumn{2}{|c|}{ factor 2 } & level -1 & level 0 & level +1 \\
\hline & level -1 & CS_1 & CS_2 & CS_3 \\
\cline { 2 - 5 } & level 0 & CS_4 & CS_5 & CS_6 \\
\hline & level +1 & CS_7 & CS_8 & CS_9 \\
\hline
\end{tabular}

527 Declarations

\section{$528 \quad$ Funding}

529 This project was supported by ÚNKP-19-3-I New National Excellence Program of the 530 Ministry for Innovation and Technology.

\section{Conflict of interest disclosure}

The authors declare no conflict of interest. 
533 Availability of data and material

534 Not applicable.

535 Code availability

536 Not applicable.

537 Authors' Contributions

538 Adrienn Kazsoki designed the experiments and accomplished the viscous solution preparation 539 and formulated the electrospun fibrous mats. Analyzed and evaluated the measurements and 540 wrote the manuscript. Attila Farkas performed and evaluated the Raman spectroscopy 541 measurements. Elena Mancuso, Preetam K. Sharma, Dimitrios A. Lamprou performed the 542 TEM and XPS measurements and analysis. Diána Balogh-Weiser performed the SEM 543 measurements. Romána Zelkó finalized the manuscript.

544

545

Declaration of interests

546

$547 \bigotimes$ The authors declare that they have no known competing financial interests or personal 548 relationships that could have appeared to influence the work reported in this paper.

549

550

$\square$ The authors declare the following financial interests/personal relationships which may be

551 considered as potential competing interests:

552

553

554

555

556

557

558

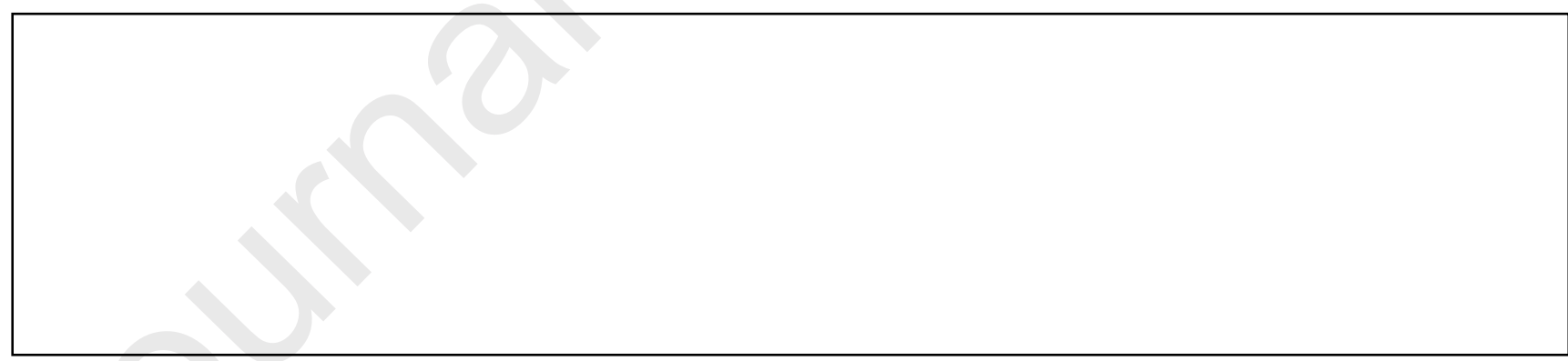

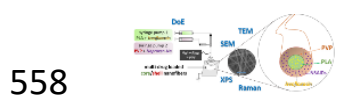

